\title{
Numerical analysis and optimization of a dual-order mode all-optical wavelength converter
}

\author{
Nielsen, Mads Lønstrup; Wolfson, David; Kloch, Allan; Bischoff, Svend
}

\author{
Published in: \\ Proceeding on Optical Communication
}

Link to article, DOI:

10.1109/ECOC.2001.989116

Publication date:

2001

Document Version

Publisher's PDF, also known as Version of record

Link back to DTU Orbit

Citation (APA):

Nielsen, M. L., Wolfson, D., Kloch, A., \& Bischoff, S. (2001). Numerical analysis and optimization of a dual-order mode all-optical wavelength converter. In Proceeding on Optical Communication (Vol. 4, pp. 576-577) https://doi.org/10.1109/ECOC.2001.989116

\section{General rights}

Copyright and moral rights for the publications made accessible in the public portal are retained by the authors and/or other copyright owners and it is a condition of accessing publications that users recognise and abide by the legal requirements associated with these rights.

- Users may download and print one copy of any publication from the public portal for the purpose of private study or research.

- You may not further distribute the material or use it for any profit-making activity or commercial gain

- You may freely distribute the URL identifying the publication in the public portal 


\title{
Numerical Analysis and Optimization of a Dual-Order Mode All-Optical Wavelength Converter
}

\author{
M. L. Nielsen, D. Wolfson, A. Kloch ${ }^{1}$, S. Bischoff, J. Mørk \\ Research Center COM, Technical University of Denmark, Build. 345, DK-2800 Lyngby, Denmark (mln@com.dtu.dk), \\ 'Now with IONAS A/S, Blokken 84, DK-3460 Birkerød, Denmark

\begin{abstract}
A numerical analysis of a dual-order mode (DOMO) wavelength converter has been carried out. We optimize the waveguide dimensions for high speed and compare to a single mode device. We also identify a cross-talk penalty when converting to wavelengths close to the original.
\end{abstract}

\section{Introduction}

All-optical wavelength conversion is regarded as a key functionality in future WDM networks, and a lot of effort has been put into the development of fast and practical converters. The most promising candidates in terms of speed are Interferometric Wavelength Converters (IWCs) based on CrossPhase Modulation (XPM) in Semiconductor Optical Amplifiers (SOAs), where $168 \mathrm{~Gb} / \mathrm{s}$ conversion has been obtained $/ 1 /$ To achieve such high speeds, operating the wavelength converter in a co-propagating configuration, that is, with the data-signal and $\mathrm{CW}$-probe propagating in the same direction, is usually required to prevent transit-time effects $/ 2 t$. However, a filter is needed at the output to separate the converted signal from the original. This introduces loss and pulse shaping $/ 2$, but most importantly, it prohibits conversion to the same wavelength, which reduces flexibility. These problems are addressed by the Dual-Order Mode (DOMO) wavelength converter, which takes care of the filtering internally by means of mode-symmetry separation, using integrated Multi-Mode Interference (MMI) couplers. Mach-Zehnder Interferometer (MZI) type wavelength converters using this technique have been successfully implemented /2-3/ and demonstrated at $20 \mathrm{~Gb} / \mathrm{s} / 4 /$. However, the limitations of these devices have not yet been clarified. In this paper we report the first numerical analysis of the performance of DOMO converters, and emphasize the characteristics, which govern the high-speed performance. In particular, we identify a cross-talk mechanism when converting to wavelengths close to the original.

\section{Principle of Operation and numerical model}

Due to the numerically exhausting task of simulating the entire DOMO MZI converter, we consider wavelength conversion by Cross-Gain Modulation (XGM) in what corresponds to one arm of the interferometer. The device is shown in Fig. 1, operating in the co-propagation scheme. The data-signal is split in a $3 \mathrm{~dB}$ coupler (a) and a phase shift of $\pi$ is applied to the signal in one of the arms, before it is injected into the access waveguides at the edges of the mode-converter combiner MMI (b). The $\mathrm{CW}$ probe

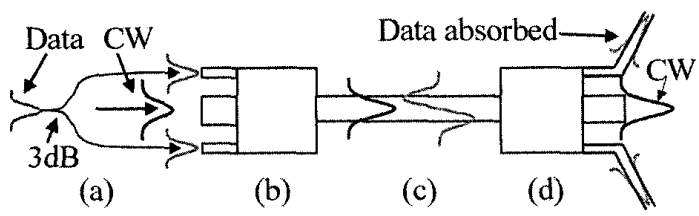

Fig. 1: Schematic of the DOMO wavelength converter. Letters refer to different sections of the device. enters the MMI through the waveguide in the center. It is noted that the operation of the $3 \mathrm{~dB}$ coupler and the phase-shifter can be carried out by a single MMI coupler, which can be an integrated part of the device $/ 2 /$. The mode-converter combiner converts the data-signal into the first-order mode of the DOMOSOA (c), and at the same time combines it losslessly with the $\mathrm{CW}$ probe carried by the fundamental mode. At the output of the DOMO-SOA, the two modes are separated in a mode-filter MMI (d), and the original data-signal is directed to unpumped waveguides and absorbed.

Since the data- and $\mathrm{CW}$ signals propagate in different transverse modes through the DOMO-SOA, they will beat with each other and create a transversal intensity pattem, which will reproduce itself periodically along the direction of propagtion. This beating phenomenon, which is only significant when the wavelength detuning between the signals is small, leads to asymmetric spatial hole-burning in the carrier density distribution, which ultimately results in cross-talk. The first-order mode, carrying the high power data-signal, is thus perturbed by the asymmetric gain, and consequently acquires an even component, which in the mode-filter will be directed to the same port as the converted signal. For large wavelength detunings, the asymmetries in the carrier distribution average out and the effect becomes insignificant. The importance of this cross-talk mechanism has been assessed, assuming an ideal mode-filter, and we have found that the converted signal is significantly distorted by pattern dependent cross-talk as the wavelength detuning is decreased below approximately $0.5 \mathrm{~nm}$.

The device, which employs waveguides of the step-index type, has been modelled using a two-dimensional Finite-Difference Beam Propagation Method (FD-BPM) with a non-uniform transversal calculation grid to limit the number of grid points necessary to obtain a solution. In the simulations we have used the paraxial approximation. The material gain is modeled as a linear, wavelength independent, function of the carrier density, and the index change due to gain saturation is also assumed linear, using a constant linewidth enhancement factor. Carrier dynamics is governed by the well-known rate equation, including the transversal carrier diffusion term. Finally, we neglect ASE, which restricts us to consider high input power.

\section{Results}

We will now present the main results of our analysis, starting with conversion speod considerations. The optical area $A_{\text {opt }}$ defined as the ratio of cross-section area to optical confinement factor, of an SOA is an important design parameter, since the $3-\mathrm{dB}$ small-signal bandwidth of the XGM response scales as /5/

$$
\mathrm{P}_{\mathrm{CW}} / \mathrm{A}_{\mathrm{op}, \mathrm{CW}}+\mathrm{P}_{\mathrm{sig}} / \mathrm{A}_{\mathrm{opt}, \mathrm{Sig}}
$$


different bias values are shown. The narrowest window with highest ER is found around $-3 \mathrm{~V}$, and is $16 \mathrm{ps}$ wide and $9.3 \mathrm{~dB}$ high. However, the overall shape of the window is influenced by the bias, so the optimum bias point, where neighbouring channels are suppressed the most, depend slightly on the bit-rate.

\section{Wavelength Conversion}

Wavelength conversion is performed with both a $\mathrm{CW}$ probe and a pulsed probe. The ML-FRL acts as a data-modulated pump at $10 \mathrm{~Gb} / \mathrm{s}$ with about $13 \mathrm{pJ}$ pulse energy $(18 \mathrm{dBm}$ average power) at $1548 \mathrm{~nm}$. The probe from the DFB laser is fixed at $1553 \mathrm{~nm}$. In the $\mathrm{CW}$ case, the probe power is about $11 \mathrm{dBm}$, and in the pulsed case about $0.3 \mathrm{dBm}$ average power $(\sim 12 \mathrm{dBm}$ peak power).
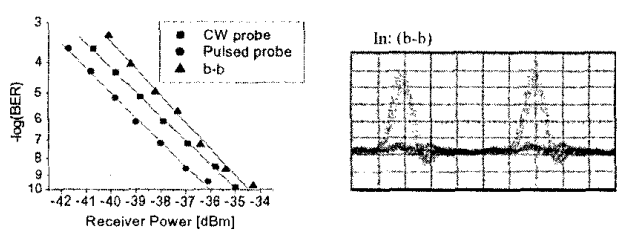

Out: CW probe
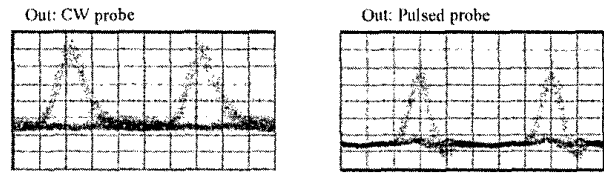

Figure 3: BER and eye diagrams for $10 \mathrm{~Gb} / \mathrm{s}$

wavelength conversion.

Figure 3 shows the BER curves and eye diagrams for the two cases, for a bias of $-2.2 \mathrm{~V}$. In both cases a negative penalty compared to the back-to-back (b-b) (directly from the transmitter to the receiver) is obtained. This is due to the nonlinearity of the transfer function, and clearly demonstrates the reshaping properties of wavelength conversion in an EAM [6]. In the CW case, the output eye clearly teveals a suppression of the " 0 "-level which is the fingerprint of the nonlinear transfer function. In the $\mathrm{CW}$ case the receiver sensitivity improvement is $0.5 \mathrm{~dB}$, whereas in the pulsed probe case, the improvement is 1.6 $\mathrm{dB}$. This better performance of the pulsed probe is primarily ascribed to the receiver's higher sensitivity to shorter pulses [8] (less average power is required to obtain the same SNR).

\section{All-optical Demultiplexing}

For demultiplexing, the GS-DFB acts as a $10 \mathrm{GHz}$ pump (at $1553 \mathrm{~nm}$ ) with only $8 \mathrm{pJ}$ pulse energy available, and the ML-FRL serves as pulse source for the 10,40 and $80 \mathrm{~Gb} / \mathrm{s}$ probe bit streams (at $1558 \mathrm{~nm}$ ) that are sent into the EAM. The probe has about $8 \mathrm{dBm}$ average power in all cases. Figure 4 shows the successful $40 / 10 \mathrm{~Gb} / \mathrm{s}$ demultiplexing results, in terms of BER curves and eye diagrams. The $10 / 10 \mathrm{~Gb} / \mathrm{s}$ demultiplexing has no power penalty compared to the back-to-back case, but a slight change in slope. Since the $10 / 10$ situation corresponds to the wavelength conversion situation, a $1.6 \mathrm{~dB}$ improvement is expected, but due to the less pump pulse energy available here the saturation of the absorption is not as effective. This is revealed by the slope change and the fact that there is no improvement in sensitivity. For the $40 / 10 \mathrm{~Gb} / \mathrm{s}$ demultiplexing there is a $2 \mathrm{~dB}$ penalty, where the major part is ascribed to the lack of pump power, but also to ISI stemming from the asymmetric switching window.
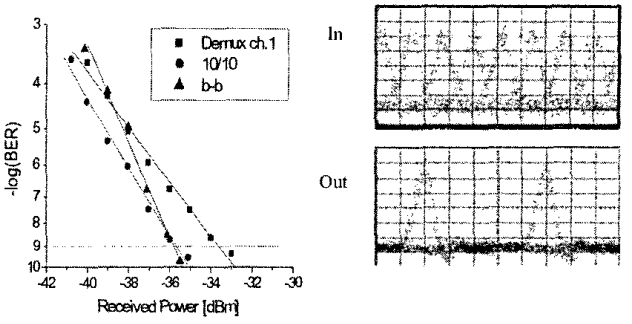

Figure 4: BER and eye diagrams for $40 / 10$ demultiplexing.

Figure 5 shows the first promising results for $80 / 10 \mathrm{~Gb} / \mathrm{s}$ demultiplexing. The EAM is set to $-3 \mathrm{~V}$ to obtain the narrowest switching window (intrinsic window $\sim 16 \mathrm{ps}$ ), and clear and open eyes are obtained for the demultiplexed channel.

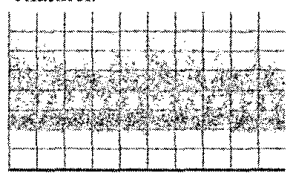

$\ln (80 \mathrm{~Gb} / \mathrm{s})$

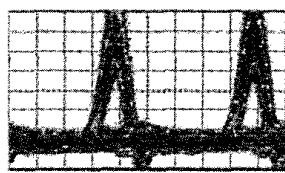

Out $(10 \mathrm{~Gb} / \mathrm{s})$
Figure 5: Eye diagrams for $80 / 10 \mathrm{~Gb} / \mathrm{s}$ demultiplexing.

The performance is limited though by the available pump power and the exponential tail of the switching window. A better perfomance is however expected at higher pump powers, and this preliminary result shows the great potential for the EAM as an all-optical demultiplexer.

\section{Conclusion}

Successful wavelength conversion at $10 \mathrm{~Gb} / \mathrm{s}$ is demonstrated with a negative penalty of $1.6 \mathrm{~dB}$. Successful all-optical demultiplexing of a $40 \mathrm{~Gb} / \mathrm{s}$ data signal down to $10 \mathrm{~Gb} / \mathrm{s}$ is demonstrated error-free, and with a $2 \mathrm{~dB}$ penalty mostly ascribed to the limited pump power. An $80 \mathrm{~Gb} / \mathrm{s}$ data signal is all-optically demultiplexed down to $10 \mathrm{~Gb} / \mathrm{s}$ yielding clear and open eyes.

\section{references}

/1/ B. Mikelsen et al. ECOC 2000, paper 6.1,1., 2000

12/ T. Otani et al. OFC'2000, ThP3-1, pp. 226-228, 2000

13/ K. Shimomura et al. ECOC 2000, paper 9.4.5, 2000

14/ K. Nishimura et al. OFC'2001, WK5-1, 2001

15/ H. Tanaka et al. OFC'2001, ME4-1, 2001

16/ S. Hejfeldt et al. J. Lightwave Tecbnol, vol. 18, no. 8 , pp. $1121-1127,2000$

171 S. Diez et al. Optics Communications, Vol. 189, Issue 4-6, pp. 241-249, 2001

/8/ S.D. Personick, Bell Syst. Tech. J., Vol. 52, no. 843, 1973 